\title{
Humidity and Inspired Oxygen Concentration During High-Flow Nasal Cannula Therapy in Neonatal and Infant Lung Models
}

\author{
Yusuke Chikata PhD, Saki Ohnishi, and Masaji Nishimura MD PhD
}

\begin{abstract}
BACKGROUND: High-flow nasal cannula therapy (HFNC) for neonate/infants can deliver up to $10 \mathrm{~L} / \mathrm{min}$ of heated and humidified gas, and $\mathrm{F}_{\mathrm{IO}_{2}}$ can be adjusted to between 0.21 and 1.0. With adults, humidification and actual $\mathrm{F}_{\mathrm{IO}_{2}}$ are known to vary according to inspiratory and HFNC gas flow, tidal volume $\left(V_{T}\right)$, and ambient temperature. There have been few studies focused on humidification and $\mathrm{F}_{\mathrm{IO}_{2}}$ in HFNC settings for neonates/infants, so we performed a bench study to investigate the influence of gas flow, ambient temperature, and respiratory parameters on humidification and actual $\mathrm{F}_{\mathrm{IO}_{2}}$ in a neonate/infant simulation. METHODS: HFNC gas flow was set at 3,5, and $7 \mathrm{~L} / \mathrm{min}$, and $\mathrm{F}_{\mathrm{IO}_{2}}$ was set at $0.3,0.5$, and 0.7 . Spontaneous breathing was simulated using a 2-bellows-in-a-box model of a neonate lung. Tests were conducted with $V_{T}$ settings of 20,30 , and $40 \mathrm{~mL}$ and breathing frequencies of 20 and $30 \mathrm{breaths} / \mathrm{min}$. Inspiratory time was $0.8 \mathrm{~s}$ with decelerating flow waveform. The HFNC tube was placed in an incubator, which was either set at $37^{\circ} \mathrm{C}$ or turned off. Absolute humidity (AH) and actual $\mathrm{F}_{\mathrm{IO}_{2}}$ were measured for $1 \mathrm{~min}$ using a hygrometer and an oxygen analyzer, and data for the final $\mathbf{3}$ breaths were extracted. RESULTS: At all settings, when the incubator was turned on, AH was greater than when it was turned off $(P<.001)$. When the incubator was turned off, as gas flow increased, AH increased $(P<.001)$; however, $V_{\mathrm{T}}$ did not affect $\mathrm{AH}(P=.16)$. As gas flow increased, actual $\mathrm{F}_{\mathrm{IO}_{2}}$ more closely corresponded to set $\mathrm{F}_{\mathrm{IO}_{2}}$. When gas flow was $3 \mathrm{~L} / \mathrm{min}$, measured $\mathrm{F}_{\mathrm{IO}_{2}}$ decreased proportionally more at each $\mathrm{F}_{\mathrm{IO}_{2}}$ setting increment $(P<.001)$. CONCLUSIONS: AH was affected by ambient temperature and HFNC gas flow. Actual $\mathbf{F}_{\mathrm{IO}_{2}}$ depended on $\mathbf{V}_{\mathrm{T}}$ when gas flow was $3 \mathrm{~L} / \mathrm{min}$. Key words: spontaneous breathing; oxygen therapy; humidification; hygrometer; oxygen analyzer; gas flow; HFNC. [Respir Care 2017;62(5):532-537. (C) 2017 Daedalus Enterprises]
\end{abstract}

\section{Introduction}

Via a cannula or nasal prongs, at higher flows than conventional oxygen therapy, high-flow nasal cannula (HFNC) oxygen therapy applied in conjunction with a

Dr Chikata is affiliated with the Medical Equipment Center, Tokushima University Hospital, 2-50-1 Kuramoto, Tokushima 770-8503, Japan. Dr Ohnishi is affiliated with the Faculty of Medicine, Tokushima University, 3-18-15 Kuramoto, Tokushima 770-8503, Japan. Dr Nishimura is affiliated with the Critical Care and Emergency Medicine, Tokushima University Graduate School, 3-18-15 Kuramoto, Tokushima 770-8503, Japan.

The authors have disclosed no conflicts of interest.

Correspondence: Masaji Nishimura MD PhD, Critical Care and Emergency Medicine, Tokushima University Graduate School, 3-18-15 Kuramoto, Tokushima 770-8503, Japan. E-mail: nmasaji@tokushima-u.ac.jp.

DOI: $10.4187 /$ respcare.05319 heated humidifier delivers gas that is almost completely humidified. ${ }^{1,2}$ In addition to this physiological benefit, HFNC also provides PEEP effects, alveolar recruitment, and increased comfort and tolerance. HFNC is frequently used as a noninvasive mode of respiratory support for neonates and infants with acute respiratory failure. ${ }^{3-6}$ Higher flow decreases the dilution of oxygen by room air and also washes out anatomical and physiological dead space. This helps to improve fractions of both alveolar carbon dioxide and oxygen. The relationship between HFNC gas flow and the inspiratory flow of the patient, however, influences the actual $\mathrm{F}_{\mathrm{IO}_{2}}$. With lowflow oxygen devices, as inspiratory flow increases, actual $\mathrm{F}_{\mathrm{IO}_{2}}$ decreases. By contrast, with $\mathrm{HFNC}$, actual $\mathrm{F}_{\mathrm{IO}_{2}}$ is stable, at least for adults. ${ }^{7,8}$ In neonates and infants, however, detailed evaluation of actual $\mathrm{F}_{\mathrm{IO}_{2}}$ has been lacking.

During respiratory assistance, adequate heating and humidification maintain mucociliary function, facilitate secretion clearance, ${ }^{9}$ and help to prevent inspissation of airway secretions, destruction of airway epithelium, and onset 
of hypothermia. In a bench study of HFNC therapy for adults, we previously reported results for humidification performance: When the inspiratory flow of spontaneous breathing exceeded HFNC gas flow, absolute humidity

\section{See the Related Editorial on Page 641}

(AH) was influenced by tidal volume $\left(\mathrm{V}_{\mathrm{T}}\right){ }^{10}$ Meanwhile, ambient temperature significantly influenced the amount of condensation in the tubes. ${ }^{11}$ Because HFNC gas flow in neonates/infants is less than in adults, we conjectured that the $\mathrm{AH}$ of gas provided by HFNC to neonates/infants might be lower than expected. In addition, neonates/infants are sometimes put in incubators maintained at $37^{\circ} \mathrm{C}$, and it is also usual, for example, after major surgeries to place young patients on an infant warmer. Due to ambient temperature differences inside and outside incubators, when HFNC is applied under these different conditions, the amount of condensation in the HFNC tube may affect the gas temperature and humidity of the delivered gas and decrease these values below expected levels. Because insufficient data have been published to reliably establish relationships between HFNC gas flow, ambient temperature, and $\mathrm{V}_{\mathrm{T}}$ and $\mathrm{HFNC}$ gas temperature and humidity during HFNC for neonates/infants, we designed a bench study to investigate these factors. In addition, we evaluated the relationship of actual $\mathrm{F}_{\mathrm{IO}_{2}}$ and $\mathrm{V}_{\mathrm{T}}$ to gas flow.

\section{Methods}

\section{Experimental Apparatus}

We set up an air/oxygen blender with a flow meter (OA2000, San-You Technology, Ltd, Saitama, Japan), auto-fill humidification chamber (MR290, Fisher \& Paykel, Auckland, New Zealand), and heated humidifier (MR850, Fisher \& Paykel) (Fig. 1). A breathing circuit for HFNC therapy (RT330, Fisher \& Paykel) was connected between the heated humidifier and nasal prongs. We made 2 holes in a polyvinyl chloride cylinder to simulate the external nares of a neonate (width, $5 \mathrm{~mm}$; depth, $4 \mathrm{~mm}$ ). The prongs of the nasal cannula (OPT314, Fisher \& Paykel) were inserted into these holes. The external nares were connected to a 2-bellows-in-a-box model lung (San-You Technology) via a standard ventilator circuit for neonates/infants (DAR 306P8193, Covidien, Mansfield, MA). Mixing of inspired and expired gases was prevented by inserting one-way valves. The whole circuit was placed in an incubator (V-2100G, catalog number 8090508, Atom Medical, Tokyo, Japan). Temperature and relative humidity were measured, in the simulated trachea, with a hygrometer (Moiscope, Senko Medical, Tokyo, Japan). Oxygen concentration was measured with an oxygen analyzer (LZ100, San-

\section{QUICK LOOK}

\section{Current knowledge}

HFNC therapy for neonates and infants can deliver up to about $10 \mathrm{~L} / \mathrm{min}$ of heated and humidified medical gas to the patient via a wide bore nasal cannula. The beneficial effects of HFNC derive, in part, from better gas warming and humidification than other modes of oxygen delivery: It provides superior humidification and stable $\mathrm{F}_{\mathrm{IO}_{2}}$. It has remained unclear, however, whether actual humidity and $\mathrm{F}_{\mathrm{IO}_{2}}$ are influenced by ambient temperature or respiratory parameters.

\section{What this paper contributes to our knowledge}

The absolute humidity (AH) of supplied HFNC gas was significantly dependent on ambient temperature: Under cooler conditions, AH was lower than expected. $\mathrm{AH}$ increased along with increasing HFNC gas flow. As HFNC gas flow increased, the gap between actual $\mathrm{F}_{\mathrm{IO}_{2}}$ and set $\mathrm{F}_{\mathrm{IO}_{2}}$ narrowed. At gas flow of $3 \mathrm{~L} / \mathrm{min}$, at each $\mathrm{F}_{\mathrm{IO}_{2}}$ setting increment, as $\mathrm{V}_{\mathrm{T}}$ increased, measured $\mathrm{F}_{\mathrm{IO}_{2}}$ decreased proportionally more. When $\mathrm{F}_{\mathrm{IO}_{2}}$ was set at 0.7 , with gas flows of 5 and $7 \mathrm{~L} / \mathrm{min}$, at $\mathrm{V}_{\mathrm{T}} 40 \mathrm{~mL}$, actual $\mathrm{F}_{\mathrm{IO}_{2}}$ decreased.

You Technology) upstream from the model lung. At the opening of the model lung, flow was measured with a pneumotachometer (4700 series, 0-160 L/min, Hans Rudolph, Shawnee, Kansas) and a differential pressure transducer (TP-602T, $\pm 5 \mathrm{~cm} \mathrm{H}_{2} \mathrm{O}$, Nihon Kohden, Tokyo, Japan). $V_{T}$ was calculated by digital integration of flow signals. The hygrometer was calibrated at 2 points using a heating and cooling unit (HHC-51, Senko Medical); the oxygen analyzer was calibrated at $\mathrm{F}_{\mathrm{IO}_{2}}$ of 0.21 and 1.0, and the pneumotachometer was calibrated using a super syringe. All signals were sampled at $10 \mathrm{~Hz} / \mathrm{ch}$ annel using data acquisition software (WinDaq, Dataq Instruments, Akron, Ohio), via an analog/digital converter (DI-148, Dataq Instruments) and stored on a computer.

\section{Simulated Spontaneous Breathing}

Spontaneous breathing was simulated using a 2-bellowsin-a-box model neonate lung. The model lung comprises 2 bellows in an airtight plastic box. The upper bellows functions as the lung, and the lower bellows functions as the diaphragm. The space between the bellows and box acts as the pleural cavity. The diaphragm bellows is connected to a T-tube, where the Venturi effect of jet flow creates negative pressure inside the diaphragm bellows. This jet flow was regulated to create $\mathrm{V}_{\mathrm{T}}$ of 20,30 , and $40 \mathrm{~mL}$ at 20 and 30 breaths/min. Inspiratory time was $0.8 \mathrm{~s}$ with a kind of 


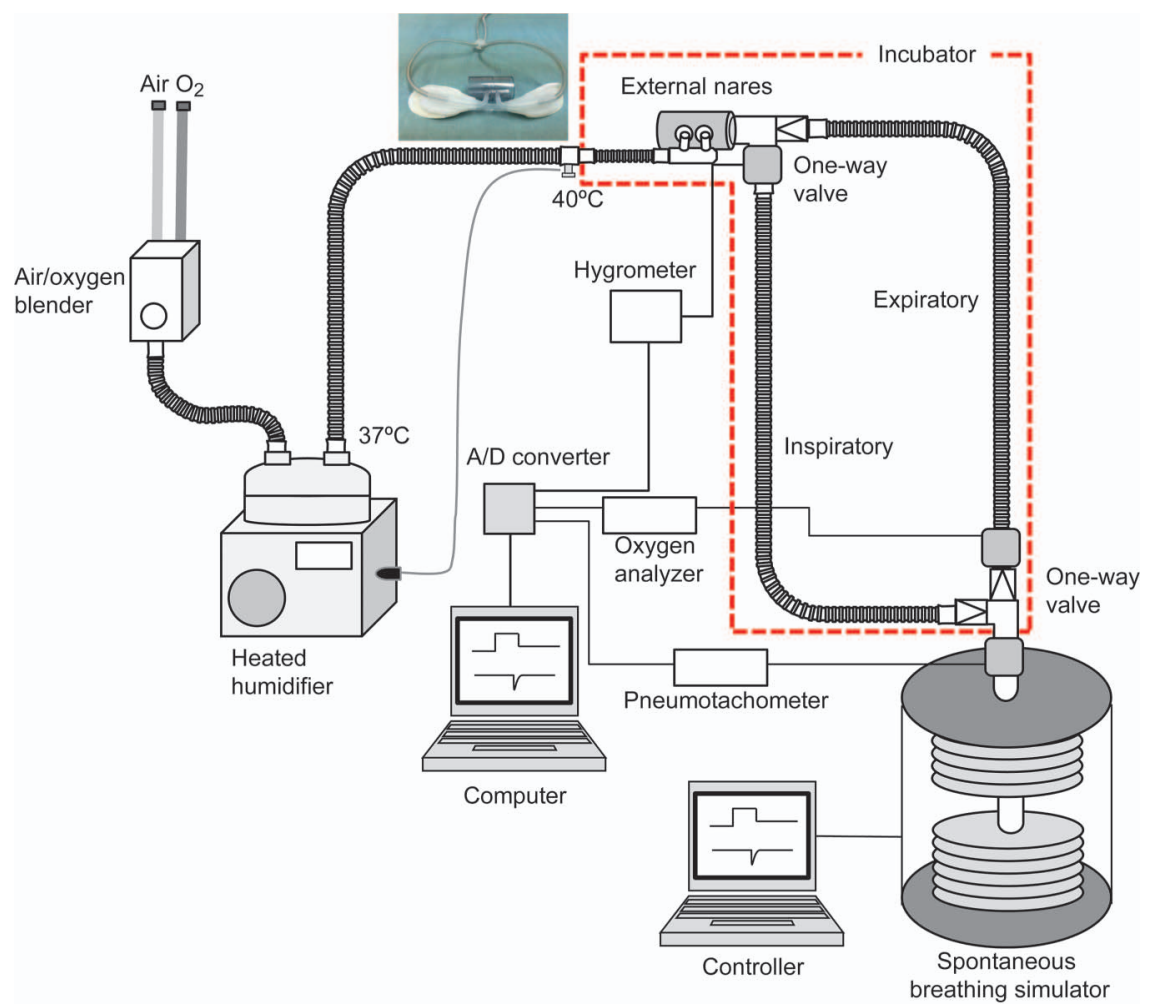

Fig. 1. Experimental apparatus. The high-flow nasal cannula (HFNC) system incorporated an air/ $\mathrm{O}_{2}$ blender with flow meter and a heated humidifier. The nasal cannula for HFNC therapy was connected to the manufacturer's standard circuit. To receive the prongs, we made 2 holes in a polyvinyl chloride cylinder to simulate the external nares of a neonate (width, $5 \mathrm{~mm}$; depth, $4 \mathrm{~mm}$ ). The external nares were connected to a 2-bellows-in-a-box type model lung for neonate via a standard ventilator circuit. In a standard ventilator circuit, one-way valves were connected to prevent mixing of inspired and expired gases. To evaluate simulated $\mathrm{V}_{\mathrm{T}}$, a pneumotachometer with a differential pressure transducer was connected between the T-piece and the outlet of the model lung. Humidity of inspired gas downstream of the external nares was measured using a hygrometer. $\mathrm{F}_{\mathrm{IO}_{2}}$ was measured downstream of the model lung.

decelerating flow waveform, and inspiratory peak flow was $2.2,3.7$, and $5.2 \mathrm{~L} / \mathrm{min}$.

\section{Experimental Settings}

HFNC gas flow was 3,5 , and $7 \mathrm{~L} / \mathrm{min}$, and $\mathrm{F}_{\mathrm{IO}_{2}}$ was set at $0.3,0.5$, and 0.7 . Gas flow was measured with a pneumotachometer with a differential pressure transducer at the outlet of the flow meter. The heated humidifier was set to invasive mode $\left(40^{\circ} \mathrm{C} /-3\right)$, and the incubator was set at $37^{\circ} \mathrm{C}$. All protocols were also repeated under the same varied conditions but with the incubator switched off.

At each change of experimental setting, we allowed $\geq 20$ min for stabilization. AH of inspired gas and actual $\mathrm{F}_{\mathrm{IO}_{2}}$ of expiratory gas were measured for $1 \mathrm{~min}$, and results for the final three breaths were extracted.

\section{Statistics}

The results are expressed as mean $\pm \mathrm{SD}$. Analysis of variance was performed using repeated measures. All statistical tests were 2 -sided, and $P<.01$ was considered statistically significant. All statistical analysis was performed using commercial software (SPSS 11.01, SPSS, Chicago, Illinois).

\section{Results}

The $\mathrm{V}_{\mathrm{T}}$ of simulated spontaneous breathing was $24.1 \pm 2.1,34.8 \pm 2.7$, and $43.6 \pm 2.2 \mathrm{~mL}$. When the incubator was turned on, the temperature in the incubator was $36.9 \pm 0.2^{\circ} \mathrm{C}$ and $\mathrm{AH}$ was $35.5 \pm 0.7 \mathrm{mg} / \mathrm{L}$; when the incubator was turned off, the temperature was $26.1 \pm 0.6^{\circ} \mathrm{C}$ and $\mathrm{AH}$ was $16.5 \pm 1.0 \mathrm{mg} / \mathrm{L}$. When $\mathrm{F}_{\mathrm{IO}_{2}}$ was set to 0.3 , 0.5 , and 0.7 , at the outlet of the flow meter, $\mathrm{F}_{\mathrm{IO}_{2}}$ was $0.30 \pm 0.002,0.50 \pm 0.001$, and $0.70 \pm 0.003$. HFNC gas flow was $3.1 \pm 0.1,5.0 \pm 0.1$, and $7.1 \pm 0.1 \mathrm{~L} / \mathrm{min}$.

\section{Effect of Respiratory Parameters on Humidification}

AH changed according to the temperature inside the incubator: At all experimental settings, it was significantly higher when the incubator was turned on $(P<.001)$. When the incubator was turned off, AH increased as HFNC 
gas flow increased $(P<.001)$ but was unaffected by changes in $\mathrm{V}_{\mathrm{T}}(P=.16)$. When the incubator was turned on, $\mathrm{AH}$ was constant regardless of gas flow and $\mathrm{V}_{\mathrm{T}}$ (Table 1 and Fig. 2); as breathing frequency increased, however, so $\operatorname{did}$ AH $(P<.001)$.

\section{Effect of Respiratory Parameters on Actual $\mathrm{F}_{\mathrm{IO}_{2}}$}

As HFNC gas flow increased, actual $\mathrm{F}_{\mathrm{IO}_{2}}$ more closely corresponded to set $\mathrm{F}_{\mathrm{IO}_{2}}$ values; for each increment in $\mathrm{F}_{\mathrm{IO}_{2}}$ setting, at $3 \mathrm{~L} / \mathrm{min}$ gas flow, as $\mathrm{V}_{\mathrm{T}}$ increased, actual $\mathrm{F}_{\mathrm{IO}_{2}}$ decreased $(P<.001)$. When $\mathrm{F}_{\mathrm{IO}_{2}}$ was set at 0.7 , with gas flows of 5 and $7 \mathrm{~L} / \mathrm{min}$, at $\mathrm{V}_{\mathrm{T}}=40 \mathrm{~mL}$, actual $\mathrm{F}_{\mathrm{IO}_{2}}$ decreased $(P<.001)$ (Fig. 3 and Table 2). Breathing frequency did not affect $\mathrm{F}_{\mathrm{IO}_{2}}(P=.37)$.

\section{Discussion}

In a bench study simulation of HFNC ventilatory assistance for neonates/infants, we investigated the effects of different rates of gas flow, $\mathrm{V}_{\mathrm{T}}$, breathing frequency, and ambient temperature on actual $\mathrm{F}_{\mathrm{IO}_{2}}$ and $\mathrm{AH}$ during HFNC. When the incubator was turned on, internal ambient tem-

Table 1. Effect of Tidal Volume and High-Flow Nasal Cannula Gas Flow on Absolute Humidity

\begin{tabular}{llll}
\hline \hline \multirow{2}{*}{ Flow (L/min) } & \multicolumn{3}{c}{ Absolute Humidity (Mean $\pm \mathrm{SD} \mathrm{mg} / \mathrm{L})$} \\
\cline { 2 - 4 } & $\mathrm{V}_{\mathrm{T}}=20 \mathrm{~mL}$ & $\mathrm{~V}_{\mathrm{T}}=30 \mathrm{~mL}$ & $\mathrm{~V}_{\mathrm{T}}=40 \mathrm{~mL}$ \\
\hline Incubator turned off & & & \\
3 & $27.3 \pm 0.8$ & $27.4 \pm 0.4$ & $27.0 \pm 0.2$ \\
5 & $29.6 \pm 0.2$ & $29.6 \pm 0.4$ & $29.3 \pm 0.3$ \\
7 & $31.1 \pm 0.9$ & $31.1 \pm 0.8$ & $31.1 \pm 0.9$ \\
Incubator turned on & & & \\
3 & $39.3 \pm 0.8$ & $39.0 \pm 0.5$ & $39.4 \pm 0.4$ \\
5 & $39.0 \pm 1.2$ & $39.4 \pm 0.9$ & $39.6 \pm 0.7$ \\
7 & $39.4 \pm 0.5$ & $39.9 \pm 0.4$ & $40.1 \pm 0.5$ \\
& & & \\
$\mathrm{~V}_{\mathrm{T}}=$ tidal volume & & & \\
\hline
\end{tabular}

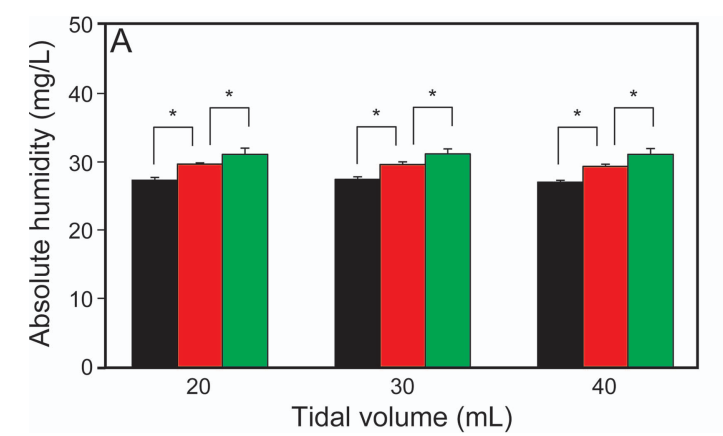

perature was maintained at $37^{\circ} \mathrm{C}$. We surmise that because vapor inside the inspiratory tube was not lost as condensation, AH was constant regardless of HFNC gas flow and $\mathrm{V}_{\mathrm{T}}$. When the inspiratory flow of spontaneous breathing is higher than HFNC gas flow, theoretically, AH would decrease as $\mathrm{V}_{\mathrm{T}}$ increases because more ambient air is inhaled by the patient. When the incubator was turned on, both the temperature and $\mathrm{AH}$ in the surrounding environment were high; consequently, $\mathrm{AH}$ was independent of the relationship between HFNC gas flow and $\mathrm{V}_{\mathrm{T}}$. When the incubator was turned off, the temperature fell to $26.1 \pm 0.6^{\circ} \mathrm{C}$, and AH fell to $16.5 \pm 1.0 \mathrm{mg} / \mathrm{L}$. Chikata et al ${ }^{12}$ reported that gas temperature in ventilator circuits that do not have a heater wire fell quickly across a short flow distance, and ambient temperature played a role. ${ }^{11}$ Moreover, HFNC gas flow for neonates/infants is slower than for adults, and ventilatory gas spends relatively more time inside the circuit. We conjecture that, at the lower ambient temperature when the incubator was switched off, vapor was lost as condensation, and this resulted in lower AH. To prevent the distal temperature probe being warmed by an ambient temperature inside an incubator, it is placed outside an incubator. The distance from the distal temperature probe to nasal prongs is relatively long, and it could be another reason why $\mathrm{AH}$ was very low when the incubator was switched off. Inside the incubator, ambient humidity was also lower, and, at high $\mathrm{V}_{\mathrm{T}}$, inspired gas could have been diluted by ambient air, which would also reduce AH. Generally, preterm infants and neonates are put inside an incubator during critical illness; however, it is also usual for infants and neonates to be placed under an infant warmer, especially after surgery. Although ambient temperature would not be as high as inside an incubator, it is likely that AH during HFNC oxygen therapy would be lower than expected. In addition, if the distal temperature probe is warmed directly by a ceramic heater, then servo-control would be disrupted, and $\mathrm{AH}$ would be greatly reduced. $\mathrm{AH}$ could be much lower than would be expected when HFNC is applied for neonates/infants outside an incubator.

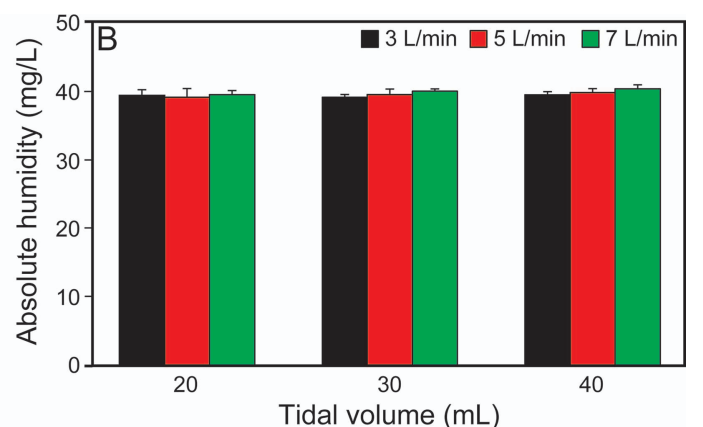

Fig. 2. Effect of respiratory parameters on absolute humidity (AH). At all settings, when the incubator was on, AH was statistically significantly greater than when it was off. When the incubator was off $(A)$, as HFNC gas flow increased, AH increased; when the incubator was on (B), AH was independent of HFNC gas flow and $\mathrm{V}_{\mathrm{T}}$. ${ }^{*} P<.001$. 

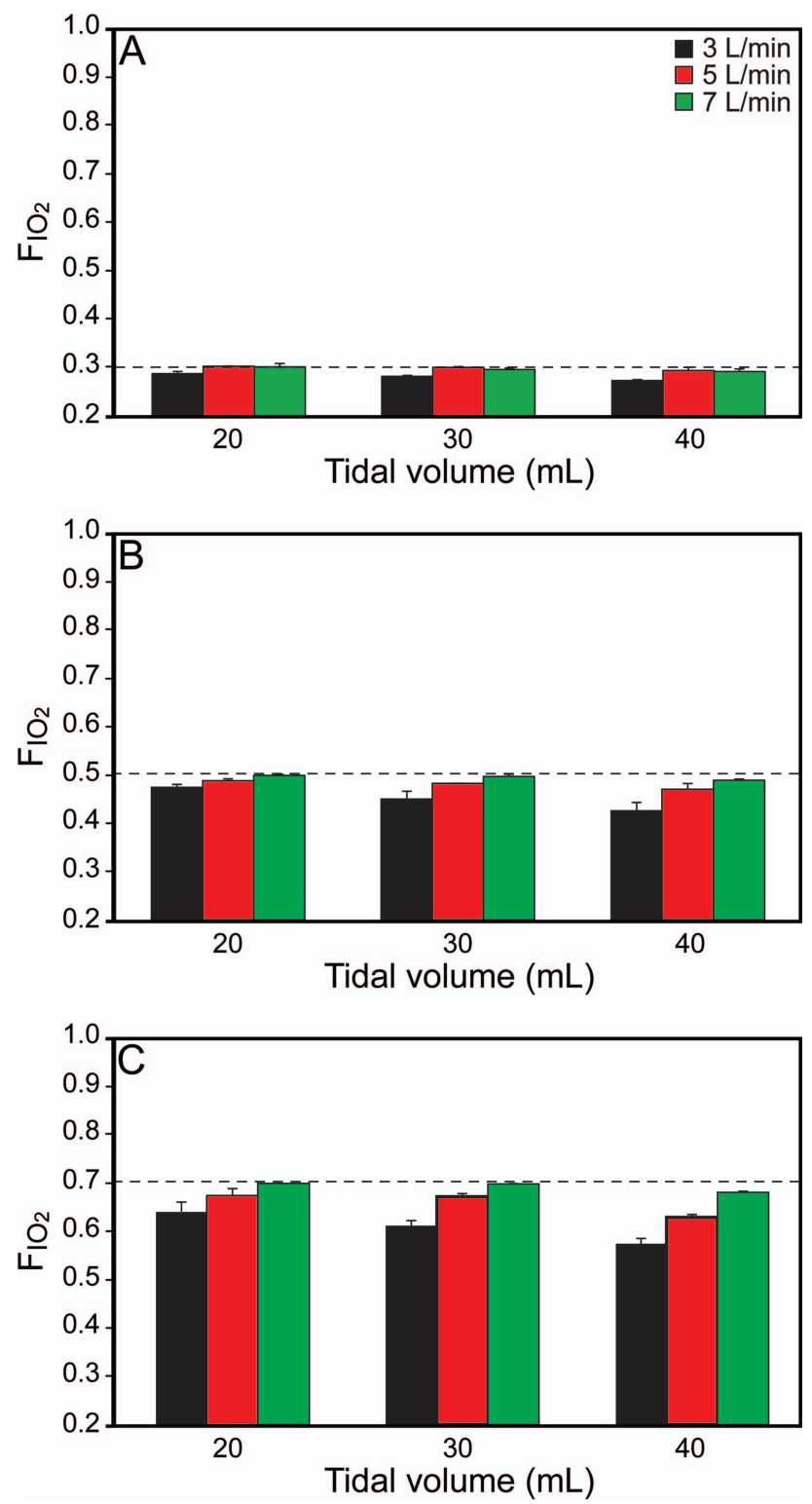

Fig. 3. Effect of respiratory parameters on actual $\mathrm{F}_{\mathrm{IO}_{2}}$. As HFNC gas flow increased, actual $\mathrm{F}_{\mathrm{IO}_{2}}$ reached the values set for $\mathrm{F}_{1 \mathrm{O}_{2}}$. With flow of $3 \mathrm{~L} / \mathrm{min}$, as $\mathrm{V}_{\mathrm{T}}$ increased, actual $\mathrm{F}_{\mathrm{IO}_{2}}$ decreased at each $\mathrm{F}_{\mathrm{IO}_{2}}$ setting increment. When $\mathrm{F}_{1 \mathrm{O}_{2}}$ was set at 0.7 , with flows of 5 and 7 $\mathrm{L} / \mathrm{min}$, at $\mathrm{V}_{\mathrm{T}} 40 \mathrm{~mL}$, actual $\mathrm{F}_{\mathrm{IO}_{2}}$ decreased. Dashed lines represent set $\mathrm{F}_{\mathrm{IO}_{2}}$.

By contrast, differences inside the incubator did not influence actual $\mathrm{F}_{\mathrm{IO}_{2}}$. Assuming that all of the HFNC gas flow is inhaled, actual $\mathrm{F}_{\mathrm{IO}_{2}}$ would depend on the relationship between the inspiratory flow of spontaneous breathing and HFNC gas flow. When inspiratory flow is less than HFNC gas flow, the patient would inhale only the gas delivered via $\mathrm{HFNC}$, and actual $\mathrm{F}_{\mathrm{IO}_{2}}$ would correspond with set $\mathrm{F}_{\mathrm{IO}_{2}}$. Only when inspiratory flow is greater than HFNC gas flow would the patient inhale both delivered gas and ambient air. When inspiratory time was set at $0.8 \mathrm{~s}$
Table 2. Effect of Tidal Volume and High-Flow Nasal Cannula Gas Flow on Actual $\mathrm{F}_{\mathrm{IO}_{2}}$

\begin{tabular}{lcccc}
\hline \hline & \multirow{4}{*}{$\begin{array}{c}\text { Flow } \\
\text { Set } \mathrm{F}_{\mathrm{IO}_{2}}\end{array}$} & \multicolumn{3}{c}{ Measured $\mathrm{F}_{\mathrm{IO}_{2}}($ Mean $\pm \mathrm{SD})$} \\
\cline { 3 - 5 } & & $\mathrm{V}_{\mathrm{T}}=20 \mathrm{~mL}$ & $\mathrm{~V}_{\mathrm{T}}=30 \mathrm{~mL}$ & $\mathrm{~V}_{\mathrm{T}}=40 \mathrm{~mL}$ \\
\hline 0.3 & 3 & $0.29 \pm 0.51$ & $0.28 \pm 0.24$ & $0.27 \pm 0.19$ \\
& 5 & $0.30 \pm 0.05$ & $0.30 \pm 0.11$ & $0.29 \pm 0.69$ \\
0.5 & 7 & $0.30 \pm 0.71$ & $0.30 \pm 0.33$ & $0.29 \pm 0.55$ \\
& 3 & $0.47 \pm 0.68$ & $0.45 \pm 1.64$ & $0.43 \pm 1.72$ \\
& 5 & $0.49 \pm 0.35$ & $0.48 \pm 0.04$ & $0.47 \pm 1.22$ \\
0.7 & 7 & $0.50 \pm 0.13$ & $0.50 \pm 0.44$ & $0.49 \pm 0.04$ \\
& 3 & $0.64 \pm 1.95$ & $0.61 \pm 1.01$ & $0.57 \pm 1.11$ \\
& 5 & $0.67 \pm 1.44$ & $0.67 \pm 0.59$ & $0.63 \pm 0.57$ \\
& 7 & $0.70 \pm 0.05$ & $0.70 \pm 0.05$ & $0.68 \pm 0.22$ \\
\hline $\mathrm{V}_{\mathrm{T}}=$ tidal volume & & & \\
\hline
\end{tabular}

with a decelerating flow waveform and $\mathrm{V}_{\mathrm{T}}$ was set at 20 , 30 , and $40 \mathrm{~mL}$, corresponding peak inspiratory flows were 2.2, 3.7, and 5.2 L/min. When HFNC gas flow was $7 \mathrm{~L} / \mathrm{min}$, while delivered flow was higher than peak inspiratory flow, measured $\mathrm{F}_{\mathrm{IO}_{2}}$ was lower than set $\mathrm{F}_{\mathrm{IO}_{2}}$. As $\mathrm{V}_{\mathrm{T}}$ increased, $\mathrm{F}_{\mathrm{IO}_{2}}$ decreased, although not by much. HFNC is an open system, and even with high-flow delivery, it is possible for the patient to inhale ambient air. In line with previous findings, the difference between set $\mathrm{F}_{\mathrm{IO}_{2}}$ and measured $\mathrm{F}_{\mathrm{IO}_{2}}$ was more apparent when set $\mathrm{F}_{\mathrm{IO}_{2}}$ was high because the difference between the set $\mathrm{F}_{\mathrm{IO}_{2}}$ and the $\mathrm{F}_{\mathrm{IO}_{2}}$ of air (0.21) was greater; consequently, equivalent volumes of ambient air contamination resulted in greater difference.

This study has some limitations. Derived from a bench study, the findings cannot be directly applied to clinical settings. In addition, the present study was done using only one inspiratory flow waveform, and the nasal prongs were firmly fixed into the external nares. In real life, peak inspiratory flow varies both from patient to patient and breath by breath. Finally, the $V_{T}$ of patients with respiratory failure is greater than the $\mathrm{V}_{\mathrm{T}}$ settings we tested.

\section{Conclusions}

In a bench study of simulated HFNC therapy for neonates and infants, we investigated humidification performance and actual $\mathrm{F}_{\mathrm{IO}_{2}}$ under different spontaneous breathing and ambient temperature conditions. $\mathrm{AH}$ was statistically significantly affected by HFNC gas flow and ambient temperature. When HFNC is used together with infant warming, AH could be lower than expected; we should carefully observe vital signs and phlegm condition when applying HFNC to small infants outside an incubator. 


\section{Humidity and $\mathrm{F}_{\mathrm{IO}_{2}}$ IN A NeOnatal/Infant HFNC Model}

\section{REFERENCES}

1. Nishimura M. High-flow nasal cannula oxygen therapy in adults: physiological benefits, indication, clinical benefits, and adverse effects. Respir Care 2016;61(4):529-541.

2. Dani C, Pratesi S, Migliori C, Bertini G. High flow nasal cannula therapy as respiratory support in the preterm infant. Pediatr Pulmonol 2009;44(7):629-634.

3. Kugelman A, Riskin A, Said W, Shoris I, Mor F, Bader D. A randomized pilot study comparing heated humidified high-flow nasal cannulae with NIPPV for RDS. Pediatr Pulmonol 2015;50(6):576-583.

4. Pham TM, O'Malley L, Mayfield S, Martin S, Schibler A. The effect of high flow nasal cannula therapy on the work of breathing in infants with bronchiolitis. Pediatr Pulmonol 2015;50(7):713-720.

5. Collins CL, Holberton JR, Barfield C, Davis PG. A randomized controlled trial to compare heated humidified high-flow nasal cannulae with nasal continuous positive airway pressure postextubation in premature infants. J Pediatr 2013;162(5):949-954.e1.

6. Yoder BA, Stoddard RA, Li M, King J, Dirnberger DR, Abbasi S. Heated, humidified high-flow nasal cannula versus nasal CPAP for respiratory support in neonates. Pediatrics 2013;131(5):e1482-e1490.
7. Ritchie JE, Williams AB, Gerard C, Hockey H. Evaluation of a humidified nasal high-flow oxygen system, using oxygraphy, capnography and measurement of upper airway pressures. Anaesth Intensive Care 2011;39(6):1103-1110.

8. Wettstein RB, Shelledy DC, Peters JI. Delivered oxygen concentrations using low-flow and high-flow nasal cannulas. Respir Care 2005; 50(5):604-609.

9. Chidekel A, Zhu Y, Wang J, Mosko JJ, Rodriguez E, Shaffer TH. The effects of gas humidification with high-flow nasal cannula on cultured human airway epithelial cells. Pulm Med 2012;2012:380686.

10. Chikata Y, Izawa M, Okuda N, Itagaki T, Nakataki E, Onodera M, et al. Humidification performance of two high-flow nasal cannula devices: a bench study. Respir Care 2014;59(8):1186-1190.

11. Chikata Y, Unai K, Izawa M, Okuda N, Oto J, Nishimura M. Inspiratory tube condensation during high-flow nasal cannula therapy: a bench study. Respir Care 2016;61(3):300-305.

12. Chikata Y, Imanaka H, Onishi Y, Ueta M, Nishimura M. Humidification during high-frequency oscillation ventilation is affected by ventilator circuit and ventilatory setting. Paediatr Anaesth 2009;19(8):779-783.

This article is approved for Continuing Respiratory Care Education credit. For information and to obtain your CRCE

(free to AARC members) visit

www.rcjournal.com

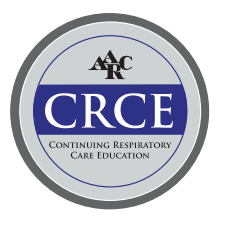

